WellBeing International

WBI Studies Repository

2011

\title{
Self-Harm in Laboratory-Housed Primates: Where Is the Evidence That the Animal Welfare Act Amendment Has Worked?
}

\author{
Jonathan Balcombe \\ Physicians Committee for Responsible Medicine \\ Hope Ferdowsian \\ Physicians Committee for Responsible Medicine \\ Debra Durham \\ Physicians Committee for Responsible Medicine
}

Follow this and additional works at: https://www.wellbeingintlstudiesrepository.org/acwp_awap

Part of the Animal Experimentation and Research Commons, Animal Studies Commons, and the Bioethics and Medical Ethics Commons

\section{Recommended Citation}

Balcombe, J., Ferdowsian, H., \& Durham, D. (2011). Self-harm in laboratory-housed primates: where is the evidence that the Animal Welfare Act amendment has worked?. Journal of applied animal welfare science, 14(4), 361-370.

This material is brought to you for free and open access by WellBeing International. It has been accepted for inclusion by an authorized administrator of the WBI Studies Repository. For more information, please contact wbisr-info@wellbeingintl.org.

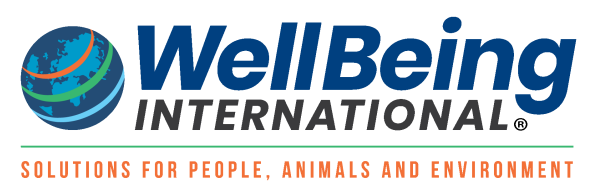




\title{
Self-Harm in Laboratory-Housed Primates: Where Is the Evidence That the Animal Welfare Act Amendment Has Worked?
}

Jonathan Balcombe, Hope Ferdowsian, and Debra Durham

Physicians Committee for Responsible Medicine

\begin{abstract}
The 1985 amendment to the United States Animal Welfare Act (AWA) to promote psychological well being of primates in the laboratory represents an acknowledgment of an important welfare problem concerning nonhuman animals. How effective has this amendment been? Perhaps the best-known contributor to psychological distress in primates in the laboratory is nonsocial housing; yet, available analyses suggest that little progress has been made in avoiding single-caging of these animals. Another way to assess psychological well being is to examine rates of self-abusive behavior in laboratory primates. If the AWA has been effective, then post-AWA self-harm rates might be lower than pre-AWA rates. However, when we attempted to determine those rates from published studies, data were too sparse to allow a rigorous statistical analysis; of 139 studies reporting primate self-harming behavior, only 9 contained data allowing estimation of self-harming behavior rates. We conclude that the current system of laboratory animal care and record keeping is inadequate to properly assess AWA impacts on primate psychological well being and that more is required to ensure the psychological well being of primates.
\end{abstract}

The psychological well being of nonhuman primates (hereafter primates) is a subject of special interest and concern (Banner, 2002; European Commission, 2002). Today, it is broadly accepted that primates have well-developed cognitive and emotional capacities and are capable of experiencing pain and distress (Cheney \& Seyfarth, 2007; de Waal, 2005; Matsuzawa, 2008). These qualities make primates vulnerable also to the psychological sequelae of prolonged confinement, social isolation, and other laboratory conditions (National Research Council, 1998). In 1985, acknowledgment of these concerns in the United States led to the enactment of an amendment to the Animal Welfare Act (AWA): "to promote the psychological well-being of primates" (AWA, 1985, §1752).

Large numbers of primates continue to be used in laboratory settings, the majority being used in the United States. According to the most recently available United States Department of Agriculture (USDA) annual report (2009), 124,417 primates were used for research, testing, and education in the United States (USDA, 2010). In Europe, 9,569 primates were used by the 27 European Union (EU) member nations in 2008, the most recent year for which data are available (Commission of the European Communities [CEC], 2010); this is more than an 8\% drop from the previous reporting year's (2005) total of 10,449 primates (CEC, 2007) despite the addition of two new EU member states. Reports and estimates 
from other nations (Japan, Switzerland, Australia, Taiwan, and Israel) indicate that more than 3,500 primates are used yearly elsewhere.

One way to assess the efficacy of the 1985 AWA provision in providing for the well being of primates in laboratories might be to compare welfare measures before and since the enactment of the AWA amendment. In this commentary, we focus on two important and widely accepted factors in the psychological well being of primates in captivity: social housing and the expression of self-harmful behavior. We also consider changes in other risk factors for psychopathology, such as early maternal separation and amount of time spent outdoors. Specifically, an increase in rates of social housing or other factors that influence well being and a decrease in rates of self-harmful behavior could be seen as signs of progress in the wake of the AWA amendment.

\section{SINGLE-HOUSING RATES}

It is widely accepted that being housed alone is a serious welfare deficit for social primates. The International Primatological Society (IPS) stipulates that "single caging on experimental grounds should always be avoided if possible" and that it "should be for as short a time as possible" (IPS, 2007, p. 16). The USDA Code of Federal Regulations stipulates that housing "... must include specific provisions to address the social needs of nonhuman primates of species known to exist in social groups in nature" (USDA, 2008, p. 108). For rhesus macaques, the proportion of time spent in individual cage-housing is a significant predictor of psychological harm as reflected by rates of self-injury and self-biting (Kraemer, Schmidt, \& Ebert, 1997; Lutz, Marinus, Chase, Meyer, \& Novak, 2003; Schapiro, 2002). Isolation for the 1 st year of life resulted in self-harming behavior rates of $100 \%$ in rhesus macaques in the studies of Harlow and colleagues (Cross \& Harlow, 1965; Harlow, Harlow, \& Suomi, 1971). Other primate species are also vulnerable to psychological distress following physical separation from conspecifics: cynomolgus monkeys (Shively, Clarkson, \& Kaplan, 1989), pigtailed macaques (Bellanca \& Crockett, 2002), and baboons (Papio hamadryas; Kessel \& Brent, 2001).

Data on pre-AWA amendment rates of single-housing of laboratory primates are lacking, so it is not possible to objectively assess the possible impact of the 1985 AWA amendment in this regard. Nevertheless, rates of single-caging of primates in U.S. laboratories remain high. A 2003 survey encompassed almost 36,000 macaques in 22 U.S. primate laboratories. The survey found that $73 \%$ of the total (including large breeding groups in outdoor corrals) were socially housed and that $54 \%$ of those animals $(17,471)$ being used in research were singly caged; however, social housing had not increased significantly in the previous decade (Baker, 2007). A formal, nonexhaustive survey by USDA Animal Care field inspectors between October 2000 and August 2001 determined that 17,093 (34.7\%) of a total 49,310 surveyed animals kept in research facilities were single-housed (USDA, 2002). The lower proportion reported by USDA may be attributable to the inclusion of individuals temporarily placed together for breeding purposes. Between 2004 and 2006 at the National Primate Research Center in Seattle, Washington, $63 \%$ of monkeys (numbering between 709 and 884 ) were singly caged (Thom \& Crockett, 2008).

Available data suggest that individual monkeys spend a substantial amount of time housed alone. Of 139 studies we identified in a literature search (see Self-Harming Behavior section), 22 reported the amount of time monkeys lived in single cages. From these, the mean time spent housed alone in studies published prior to 1991 when the AWA amendment came into effect ( $\mathrm{D}$ 8) was $3.4 \pm 3.2$ years; in studies published after $1991(n=14)$, the mean time was $3.2 \pm 2.5$ years. An ongoing, separate analysis of detailed records (1975-2008) from three U.S. laboratories involving more than 200 macaques and baboons indicates that these animals spend, on average, more than $50 \%$ of their lives caged alone 
(Balcombe \& Conlee, 2011). The aforementioned numbers are a tiny fraction of the whole, which once again precludes a meaningful assessment of possible trends in relation to the 1985 AWA amendment.

\section{OTHER RISK FACTORS}

Rearing condition appears to be an important factor in primate psychological well being. Infant monkeys reared by their mothers appear less prone to future self-harming behavior than infants nursery-reared by human caregivers or surrogate-reared with an artificial mother (Bellanca \& Crockett, 2002; Lutz, Davis, Ruggiero, \& Suomi, 2007; Lutz et al., 2003). Once again, however, data are lacking to compare pre-AWA amendment and post-AWA amendment rearing conditions; thus, it is unclear what, if any, effect the AWA amendment has had. Similarly, although there is evidence that more time spent indoors is a risk factor for the development of abnormal behaviors (Rommeck, Anderson, Heagerty, Cameron, \& McCowan, 2009), authors typically do not report this, and there are inadequate data to assess trends. Because self-harming behavior risk factors often covary (amount of time spent with mother and age at which an individual enters solitary housing), determining the relative contributions of each factor is challenging (Lutz et al., 2007; Novak, 2003).

\section{SELF-HARMING BEHAVIOR}

Incidence of self-harming behavior itself is another potential way to assess the impact of the 1985 AWA amendment. Self-harming behavior includes self-biting, self-hitting, head-banging, and hair-pulling. Selfharming behavior has been associated with psychological disorders such as anxiety in both humans and other primates (Skegg, 2005; Tiefenbacher, Novak, Lutz, \& Meyer, 2005). Self-harming behavior is a pertinent and serious concern because it is one of the most unambiguous and severe manifestations of psychological distress of primates in laboratories (Reinhardt \& Rossell, 2001).

Self-harming is a relatively common occurrence. Novak (2003) described self-directed biting as "common" in a population of 188 singly housed rhesus macaques and further reported that these bites resulted in wounds requiring veterinary attention in $14 \%$ of these monkeys. Macy, Beattie, Morgenstern, \& Arnsten (2000) estimated that self-harming behavior afflicts up to $10 \%$ of singly housed primates. A 1995 review of 238 monkeys of two species (rhesus and cynomolgus macaques), kept in three research facilities, reported self-harming behavior in 12 animals (5\%; Bayne, Haines, Dexter, Woodman, \& Evans, 1995).

Although absence of self-harming behavior does not imply that conditions for psychological well being are being met, if existing legislation (the AWA 1985 provision), regulations (the Institute for Laboratory Animal Resources Guide for the Care and Use of Laboratory Animals [ILAR], 1996), and practice help promote psychological well being, then we might expect to see a decrease in the prevalence of, and risk for, selfharming behavior. We set out to test the hypothesis that self-harming behavior rates in laboratory primates have declined since enactment of the 1985 AWA amendment. We defined self-harming behavior as self-directed abuse that may or may not cause detectable wounds. Even noninjurious self-abuse should be deemed harmful because (a) it is abnormal and virtually unknown in free-living animals and (b) it may be a precursor to injurious manifestations of the behavior (Anderson \& Chamove, 1980). Notably, reviews of behavioral pathologies in nonhuman primates suggest that they are progressive in nature and can be increasingly resistant to treatment (Cross \& Harlow, 1965; Lutz, Tiefenbacher, Meyer, \& Novak, 2004; Novak, 2003). Our approach was to conduct an online literature search (we used MEDLINE, PrimateLit, and the Environmental Enrichment for Primates databases). To ensure an unbiased assessment, we included only studies providing data on a random or a whole sample of animals. For instance, if a study reported on animals with only prior evidence of abnormal behavior or on only selfinjuring animals, we excluded the study from our analysis. For the same reason, we excluded case studies of self-harming animals and studies of self-injury induced chemically, surgically, or by any other 
reportedly deliberate method. Studies conducted outside the United States were also excluded because the animals would not fall under AWA purview.

In all, we identified 139 studies reporting primate self-harming behavior. Of these, however, only 14 provided a random sample. In all of the other 125 studies, data were nonrandomly focused on animals afflicted with abnormal behavior, precluding the option of determining rates of self-harming behavior. Of the remaining 14 studies, 2 were excluded because they were performed outside the United States; 3 others were performed at the same institution as earlier qualifying studies and therefore presented the risk that some monkeys were reported on twice.

Thus, only nine studies_four published before the 1985 AWA amendment took effect in 1991 and five published since-were eligible for inclusion. Furthermore, sample sizes in some of these studies were very small; two of the pre-AWA studies reported on just 5 animals, and the total number of primates in the pre-AWA cohort was 110 (Table 1). The post-AWA cohort was larger (1,123 animals); however, it still comprised only about $1 \%$ of the primates currently housed in American laboratories. It is unlikely that more than 5 animals in the post-AWA cohort could have been exhibiting self-harming behavior during the pre-AWA period because only one post-AWA study $(n=362$, age range 2-21 years, mean age 7.3 years, $84 \%$ under age 12 years) involved any animals old enough to have been living before 1991 (Lutz et al., 2003). It also is possible that the AWA amendment would help even those primates who were already housed and injured before implementation of the AWA amendment.

The data set was too small to permit robust statistically based assertions about self-harming behavior rates before and after the 1985 AWA amendment. Specific limitations included the following:

1. The samples represented only a small proportion (between 1 and $2 \%$ ) of the primates held in laboratories during the reporting period;

2. Definitions of what constitutes self-harming behavior varied among studies; and

3. All but 5 of the 1,233 total animals reported were of one species (rhesus macaque).

TABLE 1. Rates of Self-Harming Behavior (SHB) Reported for Nonhuman Primates in Qualifying Studies $(n=$ 9) Satisfying Inclusion and Exclusion Criteria

\begin{tabular}{|lllccc|}
\hline & Source & Species & N & $\begin{array}{c}\text { \# } \\
\text { SHB }\end{array}$ & SHB \\
\hline \multirow{2}{*}{$\begin{array}{l}\text { Before 1985 Animal Welfare } \\
\text { Act Amendment (effective } \\
\text { 1991) }\end{array}$} & Cross \& Harlow, 1965 & rhesus macaque & 84 & 15 & 18 \\
& Sackett, 1968 & rhesus macaque & 16 & 3 & 19 \\
& Peffer-Smith et al., 1983 & stumptailed macaque & 5 & 2 & 40 \\
& Line et al., 1990 & rhesus macaque & 5 & 5 & 100 \\
\hline TOTAL & & & 110 & 25 & 23 \\
\hline & Hook et al., 2002 & rhesus macaque & 105 & 74 & 69 \\
After 1985 Animal Welfare & Lutz et al., 2003 & rhesus macaque & 362 & 91 & 28 \\
Act Amendment & Alexander \& Fontenot, 2003 & rhesus macaque & 80 & 31 & 39 \\
& Lutz et al., 2007 & rhesus macaque & 345 & 25 & 7 \\
& Rommeck et al., 2009 & rhesus macaque & 231 & 132 & 57 \\
\hline TOTAL & & & 1123 & 353 & 31 \\
\hline
\end{tabular}


For several reasons, reported rates of self-harm are likely to be underestimates. Sampling methods typically monitor only a small portion of the subjects' waking time. For example, Lutz et al. (2007) observed each monkey twice a year for an average total of 55 min per subject, plus noting any cases of self-biting that were detected in the interim. Bellanca and Crockett (2002) observed each pigtailed macaque for a total of 40 min over at least 2 weeks, which is equal to or less than $0.4 \%$ of the animals' waking time. In some cases, only animals whose injuries required veterinary intervention were documented (Lutz et al., 2004; Novak, 2003). Rare behavior patterns can be missed altogether if observation sessions are brief (Martin \& Bateson, 2004).

\section{RECOMMENDATIONS}

Our attempts to assess the efficacy of the 1985 AWA amendment to promote the psychological well being of laboratory-bound primates were thwarted by a dearth of data. We conclude that there is no existing mechanism to properly monitor the effectiveness of this well-intentioned amendment. Currently, U.S. regulations do not require or facilitate organized record keeping of primate use and well being. This deficit undermines the intent of the amendment. Based on published articles and, where accessible, public laboratory records, rates of important measures such as single-housing, rearing history, and self-harming behavior can only be estimated. Few investigators or authors are reporting on these measures in their study populations. The USDA and journal editors neither require nor encourage such reporting.

Implementation of improved reporting requirements for primates used in laboratory experimentation is needed. Being able to properly assess the effectiveness of the 1985 AWA amendment for psychological well being of primates warrants a standardized approach to data collection and a more formalized reporting system. We recommend implementation of a longitudinal data collection system that includes assessment of indicators for psychological well being. This approach would include data collection on individual animals and on all laboratories that house primates. Required data collection could include onetime basic demographic information such as identification number or name, species, sex, date and place of birth, rearing history, and age at weaning. It could also include a running record of any changes in housing (including social condition), incidences of abnormal behaviors (including self-harm), and indicators of positive psychological well being such as playful and exploratory behavior. At the end of each reporting period, summary data would be extracted from these forms and provided to the USDA to include in its annual report on animal use.

Chief among the anticipated objections to our recommendation is that maintaining such a record places an additional burden on animal care staff and that leveraging the raw data into a usable summary would be unfeasible for reasons of time and expense. In fact, national primate research centers already maintain detailed records of each animal, which include information on birth and rearing; a running record of housing, protocol assignments, and experimental procedures; and data on illnesses, injuries, and interventions-including chemical agents, doses and routes of administration, and, in some cases, both abnormal behavior and environmental enrichment. Although technically these records are public, they must be obtained via the Freedom of Information Act (1996), which can be time-consuming, costly, and subject to a facility's willingness to be transparent.

\section{CONCLUSION}

The 1985 AWA amendment has raised awareness of the vulnerability of primates kept in laboratory settings, has focused more attention on their cognitive and social needs, and has stimulated efforts to provide environmental enrichment (Wolfle, 2005). The number of studies dealing with housing and with self-harming behavior in primates has also increased in recent years, reflecting a heightened concern for these issues. 


\section{ACKNOWLEDGMENT}

We thank Viktor Reinhardt and two anonymous reviewers for reviewing earlier versions of the manuscript.

\section{REFERENCES}

Alexander, S., \& Fontenot, M. B. (2003). Isosexual social group formation for environmental enrichment in adult male Macaca mulatta. AALAS [American Association for Laboratory Animal Science] 54th National Meeting Official Program, 141.

Anderson, J. R., \& Chamove,A. S. (1980). Self-aggression and social aggression in laboratory-reared macaques. Journal of Abnormal Psychology, 89, 539-550.

Animal Welfare Act. (1985). Amended by Food Security Act of 1985, Pub. Law No. 99-198, 1752(a)(2)(B).

Baker, K. (2007). Enrichment and primate centers: Closing the gap between research and practice. Journal of Applied Animal Welfare Science, 10, 49-54.

Balcombe, J., \& Conlee, K. (2011, August). Primate life in the two American laboratories. Paper submitted for 8th World Congress on Animals and Alternatives in the Life Sciences, Montreal, Canada.

Banner, M. (2002). The use of primates under the Animals (Scientific Procedures) Act (1986): Analysis of current trends with particular reference to regulatory toxicology. London, UK: The Animals Procedures Committee.

Bayne, K., Haines, M., Dexter, S., Woodman, D., \& Evans, C. (1995). Nonhuman primate wounding prevalence: A retrospective analysis. Lab Animal, 24, 40-44.

Bellanca, R. U., \& Crockett, C. M. (2002). Factors predicting increased incidence of abnormal behavior in male pigtailed macaques. American Journal of Primatology, 58, 57-69.

Brüne, M., Brüne-Cohrs, U., McGrew, W. C., \& Preuschoft, S. (2006). Psychopathology in great apes: Concepts, treatment options and possible homologies to human psychiatric disorders. Neuroscience Biobehavior Review, 30, 1246-1259.

Cheney, D. L., \& Seyfarth, R. M. (2007). Baboon netaphysics: The evolution of a social mind. Chicago, IL: University of Chicago Press.

Commission of the European Communities. (2007, November). Fifth report on the statistics on the number of animals used for experimental and other scientific purposes in the member states of the European Union. Brussels, Belgium: European Communities.

Commission of the European Communities. (2010). Sixth report on the statistics on the number of animals used for experimental and other scientific purposes in the member states of the European Union: $\operatorname{COM}(2010) \quad 511 . \quad$ Retrieved from http://ec.europa.eu/environment/chemicals/lab_animals/pdf/sec_2010_1107.pdf

Cross, H. A., \& Harlow, H. F. (1965). Prolonged and progressive effects of partial isolation on the behaviour of macaque monkeys. Journal of Experimental Research in Personality, 1, 39-49.

de Waal, F. (2005). Our inner ape. New York, NY: Riverhead.

Engh, A. L., Beehner, J. C., Bergman, T. J., Whitten, P. L., Hoffmeier, R. R., Seyfarth, R. M., \& Cheney, D. L. (2006). Behavioural and hormonal responses to predation in female chacma baboons (Papio hymadryas ursinus). Proceedings of the Royal Society of London, B, 273, 707-712.

European Commission. (2002). The welfare of nonhuman primates used in research. Retrieved from ec.europa.eu/food/fs/sc/scah/out83_en.pdf

Fabrega, H., Jr. (2006). Making sense of behavioral irregularities of great apes. Neuroscience Biobehavioral Review, 30, 1260-1273.

Freedom of Information Act. (1996). 5 U.S.C. 552, as amended by Public Law No. 104-231, 110 Stat. 3048. 
Harlow H. F., Harlow, M. K., \& Suomi, S. J. (1971). From thought to therapy: Lessons from a primate laboratory. American Science, 59, 538-549.

Hook, M. A., Lambeth, S. P., Perlman, J. E., Stavisky, R., Bloomsmith, M. A., \& Schapiro, S. J. (2002). Intergroup variation in abnormal behavior in chimpanzees (Pan troglodytes) and rhesus macaques (Macaca mulatta). Applied Animal Behavior Science, 76, 165-176.

Institute for Laboratory Animal Resources. (1996). Guide for the care and use of laboratory animals. Washington, DC: National Academy Press.

International Primatological Society. (2007). IPS international guidelines for the acquisition, care and breeding of nonhuman primates. Retrieved from http://www.internationalprimatologicalsociety.org/docs/IPS_International_Guidelines_for_the_Acq uisition_Care_and_Breeding_of_Nonhuman_Primates_Second_Edition_2007.pdf

Kessel, A., \& Brent, L. (2001). The rehabilitation of captive baboons. Journal of Medical Primatology, 30, 71-80.

Kraemer, G. W., Schmidt, D. E., \& Ebert, M. H. (1997). The behavioral neurobiology of self-injurious behavior in rhesus monkeys: Current concepts and relations to impulsive behavior in humans. Annals of the New York Academy of Sciences, 836, 12-38.

Line, S. W., Clarke, A. S., Markowitz, H., \& Ellman, G. (1990). Responses of female rhesus macaques to an environmental enrichment apparatus. Lab Animal, 24, 213-220.

Lutz, C. K., Davis, E. B., Ruggiero, A. M., \& Suomi, S. J. (2007). Early predictors of self-biting in socially housed rhesus macaques (Macaca mulatta). American Jouronal of Primatology, 69, 584-590.

Lutz, C. K., Marinus, L., Chase, W., Meyer, J., \& Novak, M. (2003). Self-injurious behavior in male rhesus macaques does not reflect externally directed aggression. Physiology and Behavior, 78, 33-39.

Lutz, C., Tiefenbacher, S., Meyer, J., \& Novak, M. (2004). Extinction deficits in male rhesus macaques with a history of self-injurious behavior. American Journal of Primatology, 63, 41-48.

Macy, J. D., Beattie, T. A., Morgenstern, S. E., \& Arnsten, A. F. (2000). Use of guanfacine to control selfinjurious behavior in two rhesus macaques (Macaca mulatta) and one baboon (Papio anubis). Comparative Medicine, 50, 419-425.

Martin, P., \& Bateson, P. (2004). Measuring behaviour: An introductory guide (2nd ed.). Cambridge, UK: Cambridge University Press.

Matsuzawa, T. (2008). Primate origins of human cognition and behavior. New York, NY: Springer.

National Research Council. (1998). The psychological well-being of nonhuman primates. Washington DC: National Academy Press.

Novak, M. A. (2003). Self-injurious behavior in rhesus monkeys: New insights into its etiology, physiology, and treatment. American Journal of Primatology, 59, 3-19.

Peffer-Smith, P. G., Smith, E. O., \& Byrd, L. D. (1983). Effects of d-amphetamine on self-aggression and posturing in stump-tail macaques. Journal of the Experimental Analysis of Behavior, 40, 313-320.

Reinhardt, V., \& Rossell, M. (2001). Self-biting in caged macaques: Cause, effect and treatment. Journal of Applied Animal Welfare Science, 4, 285-294.

Rommeck, I., Anderson, K., Heagerty, A., Cameron, A., \& McCowan, B. (2009). Risk factors and remediation of self-injurious and self-abusive behavior in rhesus macaques. Journal of Applied Animal Welfare Science, 12, 61-72.

Sackett, G. P. (1968). Abnormal behaviour in laboratory-reared rhesus monkeys. In M. W. Fox (Ed.), Abnormal behaviour in animals (pp. 293-331). Philadelphia, PA: W. B. Saunders.

Schapiro, S. J. (2002). Effects of social manipulations and environmental enrichment on behavior and cell-mediated immune responses in rhesus macaques. Pharmacology Biochemistry and Behavior, 73, 271-278.

Shively, C. A., Clarkson, T. B., \& Kaplan, J. R. (1989). Social deprivation and coronary artery atherosclerosis in female cynomolgus monkeys. Atherosclerosis, 77, 69-76.

Skegg, K. (2005). Self-harm. Lancet, 366, 1471-1483. 
Thom, J. P., \& Crockett, C. M. (2008). Managing environmental enhancement plans for individual research projects at a national primate research center. Journal of the American Association of Laboratory Animal Science, 47, 51-57.

Tiefenbacher, S., Novak, M. A., Lutz, C. K., \& Meyer, J. S. (2005). The physiology and neurochemistry of self-injurious behavior: A nonhuman primate model. Frontiers in Bioscience, 10, 1-11.

U. S. Department of Agriculture. (2002). Fall 2000 NHP housing survey for animal care. Unpublished report.

U. S. Department of Agriculture. (2008). Animal and Plant Health Inspection Service Code of Federal Regulations, Title 9, Volume 1 (Document 9CFR4.11). Washington, DC: Government Printing Office. Retrieved from http://www.aphis.usda.gov/animal_welfare/downloads/awr/awr.pdf

U. S. Department of Agriculture. (2010). Annual report animal usage by fiscal year. Animal and Plant Health Inspection Service. Retrieved from http://www.aphis.usda.gov/animal_welfare/efoia/downloads/2009_Animals_Used_In_Research.p df

Wolfle, T. L. (2005). Environmental enrichment. ILAR Journal, 46, 79-82. 